\title{
Coronary artery bypass surgery
}

\section{Choice of conduit influences outcome}

Most patients undergoing surgery to their coronary arteries nowadays receive saphenous vein grafts, but around two fifths of these patients also have an internal mammary artery graft (United Kingdom cardiac surgical register). The operative mortality for patients with normal ventricular function who undergo elective surgery should be of the order of $1 \%$ to $1 \cdot 5 \% .^{1}$

The natural history of the saphenous vein conduit has been well established over the past decade: nearly four fifths of these grafts are either stenosed or occluded 10 years after operation. ${ }^{2}$ Occlusion may be associated with thrombosis, ${ }^{3}$ intimal hyperplasia or fibroplasia, ${ }^{4}$ and atherosclerosis - the main cause of late graft failure. ${ }^{5}$ Attempts to modify these events have been made by improvements in surgical technique and by treatment with drugs postoperatively. The endothelial integrity of the vein is best maintained at surgery by reducing perioperative trauma, and pressure limited distension techniques, blood perfusate, and gentle handling have become integral parts of the current technique for vein bypass. ${ }^{67}$

Graft stenosis within months of surgery is usually due to thrombosis, and the incidence of this may be reduced by treatment with antiplatelet and anticoagulant drugs. ${ }^{2}$ McEnany et al found graft patency rates of $84 \%$ in patients given warfarin, $80 \%$ with aspirin, and $72 \%$ with placebo, but only the comparison between warfarin and placebo was significant. ${ }^{7}$ Concern regarding morbidity related to anticoagulants has sustained interest in antiplatelet drugs. ${ }^{8}$ The combination of dipyridamole and aspirin, which reduces platelet adhesiveness, ${ }^{9}$ was confirmed in clinical trials to maintain early patency in up to $92 \%$ of patients given saphenous vein grafts. ${ }^{3510}$ Later low dose aspirin alone was found to be effective," as was the antiplatelet drug ticlopidine, which gave a similar patency rate at one year. ${ }^{12}$ These and other studies have used various combinations and dosages of drugs given for variable periods. A survey of British cardiac surgeons showed the two common regimens to be dipyridamole ( $300 \mathrm{mg}$ a day, stopped at one year) and low dose aspirin ( $75 \mathrm{mg}$ a day, continued indefinitely). ${ }^{6}$ Antiplatelet drugs may reduce intimal hyperplasia, ${ }^{13}$ but protection against atheromatous change is more problematical; it may possibly be influenced by the quality of the vein used and surgical handling-as well as $\operatorname{diet}^{13}$ and the presence of diabetes, hypercholesterolaemia, and hypertriglyceridaemia. ${ }^{14}$

In contrast with saphenous vein grafts the internal mam- mary artery (usually used as a pedicled conduit left attached proximally to the subclavian artery) seems to be remarkably immune to degenerative change and occlusion. This is reflected in patency rates of $95 \%$ at 10 years after operation. ${ }^{15}$ So why is the internal mammary artery not used in every case? Saphenous vein grafting is technically easier, and historically this may have limited the application of internal mammary artery grafts. There is also an anatomical restriction: the internal mammary artery can reach only the anterior cardiac surface, allowing access to the left anterior descending coronary artery, the proximal diagonal branches, the proximal right coronary artery, and intermediate or high circumflex branches. Furthermore, most patients now require at least three coronary grafts so that even if the distribution of lesions allowed the use of both internal mammary arteries some vein grafting would still be required. In practice it is common to combine an internal mammary artery graft to the left anterior descending artery with vein grafts to the circumflex and distal right coronary branches. Experience has shown that in those patients with a requirement for high immediate revascularisation inflow - those with crescendo angina, left ventricular hypertrophy, and severe left main stem diseasesaphenous vein grafts may be a safer option. ${ }^{+13}$ Mammary grafting is relatively contraindicated in those with pulmonary hyperinflation (for fear of kinking of the graft).

The long term outlook after coronary artery bypass grafting is influenced by progression of native coronary disease as well as by graft patency so that some recurrent ischaemia is inevitable irrespective of graft considerations. Follow up, however, has shown substantial differences between patients receiving saphenous vein grafts and those receiving internal mammary artery grafts. ${ }^{15} 16$ Patients who receive at least one internal mammary artery graft to the left anterior descending artery have a lower incidence of recurrent angina, are less likely to require revisional surgery if symptoms recur, and have an improved survival compared with those with saphenous vein grafts to the left anterior descending artery. Overall, $30.6 \%$ of patients with saphenous vein grafts experience recurrent angina 10 years postoperatively as opposed to $18 \%$ of those receiving at least one internal mammary artery graft. Survival at nine years postoperatively for patients with internal mammary artery grafts is $90 \%$ as opposed to $78 \%$ in those with vein grafts alone. ${ }^{16}$

Some patients do not have any saphenous veins or the veins that they have cannot be used, and so they need alternative conduits. The choice includes arm veins, bioprosthetic 
bovine internal mammary grafts, and prosthetic tube grafts. The results with all these are either dismal or unknown. One other option is the use of the free internal mammary artery. This method extends the range of the grafts and gives results with an enhanced long term patency similar to those with pedicled internal mammary artery grafts, ${ }^{13}$ but it imposes a technically awkward requirement for a proximal aortic anastomosis and still may not provide enough conduit for all of the vessels requiring grafting. Surgeons are looking for further possible second arterial conduits, and current interest has centred on the right gastroepiploic artery being left as a pedicled graft fed from the gastroduodenal artery. ${ }^{17-19} \mathrm{It}$ should be possible to use double internal mammary artery grafts to the left anterior descending and circumflex systems supplemented by the right gastroepiploic artery to the inferior surface and so to achieve total arterial revascularisation. ${ }^{20}$

What about those grafts that have failed? Balloon angioplasty or revisional surgery are possible options. Balloon angioplasty may be effective in opening up stenoses in internal mammary artery and saphenous vein grafts, although any instrumentation in old saphenous vein grafts carries a risk of distal emboli from atheromatous or thrombotic debris. The long term outcome after graft dilatation is unknown, but

1 Cosgrove DM, Loop FD, Lytle BW, et al. Primary myocardial revascularisation. $\mathcal{f}$ Thorac Cardiovasc Surg 1984;88:673-84

2 Grondin CM, Campeau L, Lesperance J, Bourassa MG, Enjalbert M. Cemparison of late changes in internal mammary artery and saphenous vein grafts in two consecutive series of patients ten years after operation. Circulation 1984;70(suppl 1):208-12.

3 Mayer JE Jr, Lindsay WG, Castaneda W, Nicoloff DM. Influence of aspirin and dipyridamole on patency of coronary artery bypass grafts. Ann Thorac Surg 1981;31:204-10.

4 Batayias GE, Barboriak JJ, Korns ME, Pintar K. The spectrum of pathologic changes in aortocoronary saphenous vein grafts. Circulation 1977;56(suppl 2):18-22.

5 Bulkley BH, Hutchins GM. Accelerated "atherosclerosis." A morphologic study of 97 saphenous vein coronary artery bypass grafts. Circulation 1977;55:163-9.

6 Angelini GD, Bryan AJ, West RR, Newby AC, Breckenridge IM. Coronary artery bypass surgery: current practice in the United Kingdom. Thorax 1989:44:721-4.

7 McEnany MT, Salzman EW, Mundth ED, et al. The effect of antithrombotic therapy on patency renany MT, Salzman EW, Mundth ED, et al. The effect of antithrombotic therapy on
rates of saphenous vein coronary bypass grafts. F Thorac Cardiovasc Surg 1982;83:81-9.

rates of saphenous vein coronary bypass grafts. F Thorac Cardiovasc Surg 1982;83:81-9.
Verstraete M. Are agents affecting platelet functions clinically useful? Am f Med 1976;61:897-914.

9 Chesebro JH, Clements IP, Foster V, et al. A platelet inhibitor drug trial in coronary artery bypas operations: benefit of perioperative dipyridamole and aspirin therapy on early vein graft patency. NEngl F Med 1982;307:73-8.

10 Rajah SM, Salter MCP, Donaldson DR, et al. Acetylsalicylic acid and dipyridamole improve the early patency of aortocoronary bypass grafts. $\mathcal{F}$ Thorac Cardiovasc Surg 1985;90:373-7.

11 Lorenz RL, Schacky CV, Weber M, et al. Improved aortocoronary bypass patency by low-dose aspirin $(100 \mathrm{mg}$ daily): effects on platelet aggregation and thromboxane formation. Lancet $1984 ; i: 1261-4$ reoperation is associated with $90 \%$ survival at five years and $75 \%$ at 10 years. ${ }^{21}$

In the early 1980s the concept of "complete revascularisation" was popular; it was based on the belief that grafts should be made to all vessels with stenoses tighter than $50 \%$. We are now more realistic, taking account of the uncertain progression of underlying coronary artery disease. Given the likelihood that (for the near future, at least) saphenous vein grafts will continue in common usage, coronary surgery should be seen as a palliative rather than a curative procedure. While increased use of the internal mammary artery is indicated, particularly to the left anterior descending coronary artery, restriction of grafting to coronary arteries that have severe $(>70 \%)$ stenoses and that will allow adequate $(>40 \mathrm{ml} / \mathrm{min}$ ) run off might represent the wise approach for the coming decade.

E W J CAMERON Consultant Cardiothoracic Surgeon

W S WALKER Consultant Cardiothoracic Surgeon

Royal Infirmary and City Hospital, Edinburgh EH10 5SB

12 Limet R, David J-L, Magotteaux P, Larock M-P, Rigo P. Prevention of aortocoronary bypass graft occlusion. Beneficial effect of ticlopidine on early and late patency rates of venous coronar bypass grafts: a double-blind study. $\mathcal{F}$ Thorac Cardiovasc Surg 1987;94:773-83.

13 Loop FD. Coronary revascularisation: distal anastomoses preceding proximal anastomoses. In Grillo HC, Austen WG, Wilkins EW Jr, Mathisen DJ, Vlahakes GJ, eds, Current therapy in cardiothoracic surgery. Toronto: B C Decker, 1989:419-22.

14 Lytle BW, Loop FD, Cosgrove DM, Ratcliff DM, Easley K, Taylor PC. Long-term (5-12 years serial studies of internal mammary artery and saphenous vein coronary bypass grafts. $\mathcal{F}$ Thora Cardiovasc Surg 1985;89:248-58

15 Loop FD, Lvtle BW, Cosgrove DM, et al. Influence of the internal-mammary-artery graft on 10 year survival and other cardiac events. $N$ Engl f Med 1986;314:1-6.

16 Acinapura AJ, Rose DM, Jacobwitz IJ, et al. Internal mammary artery bypass grafting influence on recurrent angina and survival in 2100 patients. Ann Thorac Surg 1989;48:186-91.

17 Pym J, Brown PM, Charrette EJP, Parker JO, West RD. Gastroepiploic-coronary artery anastomosis: a viable alternative bypass graft. F Thorac Cardiovasc Surg 1987;94:256-9.

18 Mills NL, Everson CT. Right gastroepiploic artery: third arterial conduit for coronary artery bypass. Ann Thorac Surg 1989;47:706-11.

19 Lytle BW, Cosgrove DM, Ratcliff NB, Loop FD. Coronary artery bypass grafting with the right gastroepiploic artery. F Thorac Cardiovasc Surg 1989;97:826-31.

20 Suma $\mathrm{H}$, Takeuchi $\mathrm{A}$, Hirota $\mathrm{Y}$. Myocardial revascularisation combined arterial grafts utilising the internal mammary and the gastroepiploic arteries. Ann Thorac Surg 1989;47:712-5.

21 Lytle BW, Loop'FD, Cosgrove DM, et al. Fifteen hundred coronary reoperations. Results and determinants of early and late survival. J Thorac Cardiovasc Surg 1987;3:847-59.

\section{Providing the fetus with calcium}

\section{Dietary supplements are needed for women in high risk groups}

Necessarily, all of the calcium in the newborn infant has come from the mother. At birth the mineral content of the average mature baby is about $28 \mathrm{~g}$ of calcium and $16 \mathrm{~g}$ of phosphorus, with $99 \%$ and $85 \%$, respectively, in the skeleton. ${ }^{12}$ The combination of progressive skeletal mineralisation and exponential growth means that some $70 \%$ of this calcium is deposited in the last trimester; the net flux of calcium into the fetus towards the end of pregnancy is about $250 \mathrm{mg}$ a day. ${ }^{2}$ The control of this process requires considerable integration and collaboration between the fetal and maternal endocrine systems, which meet at the interface of the placenta.

In women who are not pregnant circulating parathyroid hormone concentrations are controlled by the amount of ionised calcium in the serum; the hormone promotes gastrointestinal calcium influx principally by activating the renal enzyme 25 -hydroxyvitamin Di- $\alpha$-hydroxylase. During pregnancy concentrations of parathyroid hormone measured by immunoradiometric assay (probably the most biologically relevant method as it measures the intact molecule) are low. This strongly suggests that other factors-possibly lowered serum concentrations of phosphate-are responsible for the activation of the enzyme during pregnancy. Other possible candidates are prolactin; oestradiol; and placental lactogen, with its growth hormone-like effect. There is equally little agreement about maternal calcitonin, with studies reporting high, low, and normal concentrations. ${ }^{+7}$

1,25-Dihydroxyvitamin D plays a key part in calcium homoeostasis. Vitamin D is produced in the skin by the action of ultraviolet light on 7-dehydroxycholesterol, forming cholecalciferol (vitamin D3), which in turn then undergoes 25-hydroxylation in the liver. The maternal concentration of vitamin $\mathrm{D}$ binding protein (which accounts for about $1 \%$ of the plasma proteins) is increased through the action of oestrogens on hepatic synthesis. ${ }^{8}$ Interpretation of total concentrations of the vitamin D metabolites is therefore complicated in pregnancy. The consensus seems to be, 